\title{
The effect of early feeding practices on growth indices and obesity at preschool children from four European countries and UK schoolchildren and adolescents
}

\author{
George Moschonis ${ }^{1}$ - Blandine de Lauzon-Guillain ${ }^{2,3}$ • Louise Jones ${ }^{4}$. \\ Andreia Oliveira ${ }^{5}$. Christina-Paulina Lambrinou ${ }^{1} \cdot$ Louiza Damianidi $^{6}$. \\ Sandrine Lioret ${ }^{2,3}$ - Pedro Moreira ${ }^{7}$ - Carla Lopes ${ }^{5}$ - Pauline Emmett ${ }^{4}$. \\ Marie Aline Charles ${ }^{2,3}$ - Yannis Manios $^{1}$ (D)
}

Received: 22 April 2016 /Revised: 29 May 2017 / Accepted: 30 June 2017 /Published online: 15 July 2017

(C) Springer-Verlag GmbH Germany 2017

\begin{abstract}
Not only healthy growth but also childhood obesity partly originate from early life. The current work aimed to examine the association of feeding practices during infancy with growth and adiposity indices in preschool children from four European countries and in UK schoolchildren and adolescents. Existing data from four European birth cohorts (ALSPAC-UK, EDEN-France, EuroPrevall-Greece and Generation XXI-Portugal) were used. Anthropometrics and body composition indices were collected. Parallel multivariate regression analyses were performed to examine the research
\end{abstract}

Communicated by Mario Bianchetti

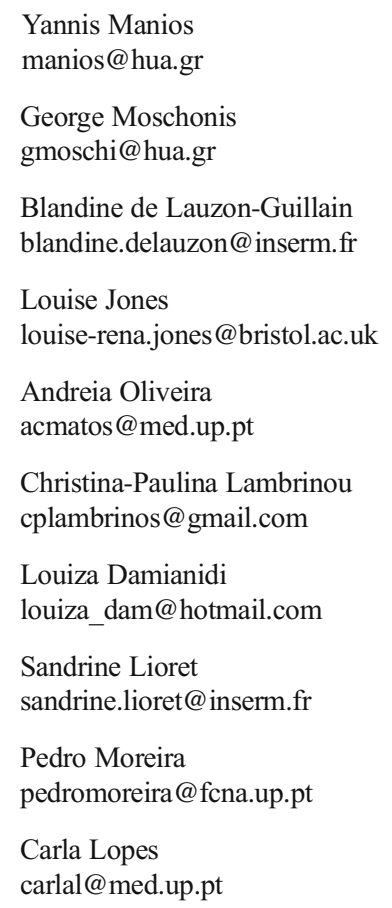

hypothesis. Overall, the analyses showed that breastfeeding and timing of complementary feeding were not consistently associated with height $z$-score, overweight/obesity, and body fat mass in children or adolescents. However, breastfeeding duration for less than 6 months was associated with lower height $z$-scores in 5 -year-old French children $(P<0.001)$ but with higher height $z$-scores in 4-year-old UK children $(P=0.006)$. Furthermore, introduction of complementary foods earlier than 4 months of age was positively associated with fat mass levels in 5-year-old French children $(P=0.026)$.

Pauline Emmett

P.M.Emmett@ bristol.ac.uk

Marie Aline Charles

marie-aline.charles@inserm.fr

1 Department of Nutrition and Dietetics, Harokopio University, 70, El.Venizelou Ave, 17671 Kallithea, Athens, Greece

2 INSERM, UMR1153 Epidemiology and Biostatistics Sorbonne Paris Cité Center (CRESS), Early Determinants of the Child's Health and Development Team (ORCHAD), 75014 Paris, France

3 Paris Descartes University, Paris, France

4 School of Social and Community Medicine, University of Bristol, Bristol, UK

5 Department of Clinical Epidemiology, Predictive Medicine and Public Health, University of Porto Medical School, Portugal and Institute of Public Health, University of Porto, Porto, Portugal

6 Department of Allergy, 2nd Pediatric Clinic, University of Athens, Athens, Greece

7 Portugal and Faculty of Nutrition and Food Sciences, Institute of Public Health, University of Porto, Porto, Portugal 
Conclusion: Early feeding practices, i.e., any breastfeeding duration and age of introduction of complementary foods, do not appear to be consistently associated with height $z$-score, overweight/obesity, and body fat mass in preschool children from four European countries and in UK schoolchildren and adolescents.

\section{What is known?}

- Healthy growth and childhood obesity partly originate from early life. What is new?

- Breastfeeding duration less than 6 months was associated with lower height z-scores in 5-year-old French children, while the opposite was observed in 4-year-old British children.

- Introduction of complementary foods earlier than 4 months was positively associated with fat mass levels in 5-year-old French children, but not in the other three countries.

- Early feeding practices did not appear to be consistently associated with growth and adiposity indices, and as such, no clear influence can be observed.

Keywords Breastfeeding · Complementary feeding · Growth $\cdot$ Obesity $\cdot$ Preschool children $\cdot$ Birth cohort

$\begin{array}{ll}\text { Abbreviations } \\ \text { ALSPAC } & \text { Avon Longitudinal Study of Parents and Children } \\ \text { BIA } & \text { Bioelectrical impedance analysis } \\ \text { BMI } & \text { Body mass index } \\ \text { CI } & \text { Confidence interval } \\ \text { DXA } & \text { Dual energy X-ray absorptiometry } \\ \text { EDEN } & \begin{array}{l}\text { Etude des Déterminants pré et post natals de la } \\ \text { santé et du développement de l'ENfant }\end{array} \\ \text { FFQ } & \text { Food-frequency questionnaire } \\ \text { HPVS } & \text { Healthy Plate Variety Score } \\ \text { SD } & \text { Standard deviation }\end{array}$

\section{Introduction}

Not only healthy growth but also overweight and obesity in childhood, adolescence, and adulthood have been reported to have part of their origins in early life [1,23,27]. The rise in the prevalence of childhood obesity over the last decades has led to the development of theories that underscore the importance of early life exposures on growth and adiposity indices in later life $[9,18]$. Among these exposures, feeding practices during infancy are thought to influence the risk of overweight and obesity later in childhood, partly by affecting early growth patterns [17].

According to recent studies, rapid infant weight gain, often seen after 4 months of age among formula-fed infants, is associated with increased risk of overweight or obesity later in childhood in developed countries $[5,14,19]$. It has also been proposed that breastfeeding may have a protective effect for overweight and obesity later in life, and this has been reported by several systematic reviews $[2,4,11,12,28]$. In a recent systematic review, it was concluded that exclusive breastfeeding for longer than 4 months of age may be associated with slower weight gain in late infancy and that any breastfeeding is protective against overweight and obesity in childhood and adolescence [11]. However, other studies suggest that the duration of breastfeeding is not associated with overweight and/or obesity in childhood or adolescence $[8,13$, 24]. Therefore, the available findings about whether duration of breastfeeding is protective or not for the development of overweight and obesity later in life are still inconsistent.

The available findings on the association between the timing of complementary feeding during infancy with growth and adiposity indices in childhood and adolescence are also inconsistent. According to a recent systematic review, although a few studies showed that the introduction of complementary feeding before the age of 4 months increases the risk for obesity, the majority of the studies included in this review reported no effect [25]. Inconsistent findings regarding the effect of the age of introduction of complementary feeding on growth and obesity later in life were also reported by another recent systematic review [22].

The aim of the present study was to examine the association between early feeding practices, i.e., any breastfeeding duration and age of introduction of complementary foods (using parallel analysis), with growth and adiposity indices, i.e., height $z$-score, fat mass levels (Bioelectrical Impedance Analysis, BIA; and Dual Energy X-ray Absorptiometry, DXA) and overweight/obesity prevalence in 4-5-year-old children from four European cohorts and in 9- and 13-yearold UK schoolchildren and adolescents.

\section{Materials and methods}

The analyses were based on four European birth cohorts: the Avon Longitudinal Study of Parents and Children (ALSPAC) cohort in the UK, the Etude des Déterminants pré et post natals de la santé et du développement de l'ENfant (EDEN) cohort in France, the EuroPrevall cohort in Greece, and the Generation XXI cohort in Portugal. This study was conducted according to the guidelines laid down in the Declaration of Helsinki, and all procedures involving human subjects were approved by each institute's ethics committee. Written informed consent was obtained from all subjects.

\section{ALSPAC}

ALSPAC is a longitudinal birth cohort study, in which pregnant women resident in a geographically defined area in southwest England with an expected delivery date between 
April 1991 and December 1992 were recruited. A cohort of 14,541 pregnant women was established, which resulted in 13,988 children alive at 12 months of age. More details can be found on the ALSPAC website (http://www.bristol.ac.uk/ alspac/). Dietary information was collected via parentcompleted food-frequency questionnaires (FFQs) at the ages of 6 and 15 months and 2, 3, 4, 7, 9, and 13 years as part of larger questionnaires that were sent through the mail with a reply envelope. In the current study, we used dietary data collected at 4 years for comparison with the other cohorts and at 9 and 13 years to assess the stability of results throughout childhood. The parent was asked to record how often the child consumed each of the foods "nowadays." Breastfeeding duration and age at introduction to various foods was obtained from parents using questionnaires provided to parents when their children were 6 and 15 months. Sociodemographic information and maternal diet (by FFQ) were collected via a questionnaire filled in by the mother during pregnancy. The children were weighed and measured routinely at several time points before 7 years of age. Up to 7000 of the children were examined in standardized research clinics annually from the age of 7 to 13 years. In addition to height and weight measurements, waist/hip/arm circumferences were measured, while BIA and DXA scans at 9 and 13-year-old children were also used to assess body fat mass. These measures have been used in the analyses performed within the current work. Data were available for 6522 4-year-old, 7540 9-year-old, and 6124 13-year-old children.

\section{French EDEN Study}

The EDEN mother-child cohort is a longitudinal study that recruited 2002 pregnant women before 24 weeks of amenorrhea (and on average at 15 weeks) in two French university hospitals in Nancy and Poitiers, between February 2003 and January 2006. A questionnaire completed during pregnancy provided data on sociodemographic factors, maternal diet (FFQ), and tobacco use. Birth data were collected from medical records. When the child was 4,8 , and 12 months, mothers completed questionnaires that were mailed to them asking for details on the feeding method of their infants and age of introduction to several food groups. They also completed a 26item child FFQ at 2 and 3 years. The questionnaire included seven categories of frequencies, ranging from never to more than once a day, and five items specifically related to fruit and vegetable consumption: vegetables or soups, raw vegetables, fresh fruit, fruit purees, and fruit juice. At 5 years, anthropometric variables were measured during a clinical exam (height, weight) and fat mass was assessed with BIA. Analyses on early feeding practices and adiposity were conducted among 1070 children and analyses including data on child's diet on 1055 children.

\section{Portuguese generation XXI birth cohort}

Generation XXI is a population-based birth cohort study established in a defined geographic area in the north of Portugal (Porto) by recruiting women in all maternity units between April 2005 and August 2006 [15]. Just before recruitment, these hospitals were responsible for $91.6 \%$ of all deliveries in the catchment area. A total of 8647 children and 8495 mothers were enrolled at baseline. Data on demographic and social conditions, lifestyles, medical history, and prenatal care were collected by trained interviewers during the first $24-72 \mathrm{~h}$ after delivery. At 15 months of age, information was collected on breastfeeding and complementary feeding (available for a subsample of 1040). At 4 years, children's dietary intakes were assessed via FFQs filled in by parents, covering the previous 6 months. The questionnaire included nine categories of frequencies, ranging from never to $>$ four times/day. Anthropometrics were obtained by trained personnel according to standard procedures, with children in underwear and barefoot. Body weight was measured to the nearest $0.1 \mathrm{~kg}$ using a digital scale (TANITA ${ }^{\circledR}$ ), and height was measured to the nearest $0.1 \mathrm{~cm}$ using a wall stadiometer $\left(\right.$ SECA $\left.^{\circledR}\right)$. BIA was performed using a tetra-polar device (BIA 101 Anniversary, Akern, Florence, Italy). The Generation XXI cohort has data for 3387 children, with a subsample of 419 having complete data for the age of introduction of complementary feeding variable as well.

\section{Greek EuroPrevall Study}

The Greek EuroPrevall cohort study is a longitudinal study conducted with 1084 newborns between October 2005 and October 2007 in 2 different clinics in Athens. The Greek EuroPrevall cohort data presented in the current study were collected as part of the EuroPrevall project [20] that was funded by the European Union (FP6-FOOD-CT-2005-514000). Standardized questionnaires were used to collect baseline data from each mother regarding her pregnancy, child's birth, dietary intake (focusing mainly on foods related to allergies), and quality of life. Sociodemographic data, such as parental educational level, parental age, occupational status, and family income were collected at birth. Follow-ups, using similar questionnaires, were conducted when children were 12, 24, and 30 months old by telephone. During these interviews, data on breastfeeding and complementary feeding practices were collected. Child's food intake was collected at 24 and 48 months by using a 80 -item FFQ covering the past 3 months. The questionnaire included 11 categories of frequencies, ranging from never to more than once a day and 24 items specifically relating to fruit and vegetable consumption. Furthermore, during the 4-year follow-up anthropometric (i.e. weight, height) and body composition (i.e. fat mass levels), assessment measurements were conducted using standard procedures and equipment (i.e. BIA in the case of body composition 
measures). Complete data were available for 309 4-year-old children.

\section{Anthropometric indices}

Body weight and standing height were measured in children using standard equipment and procedures specific to each cohort. Body mass index (BMI) was calculated as the value of weight $(\mathrm{kg})$ over the squared height $\left(\mathrm{m}^{2}\right)$. The WHO growth standards were used for the calculation of height and BMI zscores. The WHO Anthro software (WHO Anthro for personal computers, version 3. Geneva: World Health Organization; 2009. http://www.who.int/childgrowth/software/en/) was used for this calculation in Europrevall, Generation XXI, and ALSPAC. Finally, the International Obesity Task Force (IOTF) thresholds [3] were used for the categorization of children into overweight and obese using their BMI values.

\section{Body composition indices}

BIA measurements were also conducted in all cohorts with equipment and procedures that were site-specific. The resistance and reactance readings from these measurements were used for the estimation of child's fat mass levels based on the equation developed by Schaefer et al. [26]. DXA fat mass measurements were also available but only in the case of ALSPAC for 9- and 13-year-old children.

\section{Early feeding practices}

Early feeding practices included breastfeeding duration as well as age of introduction of complementary foods. Breastfeeding included both exclusive and mixed breastfeeding practices (designated as any breastfeeding), and its duration was grouped into five categories, i.e., never, $<1, \geq 1$ to $<3, \geq 3$ to $<6$, and $\geq 6$ months. Furthermore, the age of introduction of complementary foods was also grouped into five categories, i.e., $<4, \geq 4$ to $<5, \geq 5$ to $<6$, and $\geq 6$ months. However, in the case of Europrevall, data for the age of introduction of complementary foods variable were not available for the <4-month category, since the common practice in Greece is complementary feeding to be introduced after 5 months of age. Therefore, the age of introduction of complementary foods was grouped into four categories, i.e., $<5$, $\geq 5$ to $<6$, and $\geq 6$ months, for the case of Europrevall.

\section{Children's current food habits}

Children's fruit and vegetable intake and a score reflecting child's adherence to a healthy diet (Healthy Plate Variety Score-HPVS), which was based on a modified version of the food variety index for toddlers developed by Cox et al. in 1997 [6], were also used as covariates in the present study.

\section{Statistical analyses}

All statistical analyses were run in parallel in each cohort, following the same analysis plan. Associations between early feeding practices and later height $z$-score and fat mass levels (BIA, DXA) were tested by using linear regressions [beta coefficients and the respective $95 \%$ confidence intervals (beta, 95\% CI)], while the associations between early feeding practices and overweight/obesity prevalence were tested via logistic regressions [odds ratio and the respective $95 \%$ confidence intervals (OR, 95\% CI)]. The examined associations were both crude and adjusted for several potential confounders. These confounders included maternal characteristics, i.e., maternal age, educational level and pre-pregnancy BMI, child's characteristics (i.e. gender and birth weight category), fruit and vegetable consumption, and the HPVS.

The parallel analyses conducted in each country for the estimation of the descriptive data and the regression coefficients were performed by using SAS software, version 9.2 (SAS Institute Inc.) in EDEN, STATA/SE (StataCorp) version 10.0 in Generation XXI, SPSS 19.0 and 21.0 in ALSPAC and EuroPrevall, respectively. The level of statistical significance was set at $p<0.05$.

\section{Results}

\section{Descriptive statistics}

Table 1 presents some descriptive data on the characteristics of mothers (maternal age and pre-pregnancy BMI) and children (any breastfeeding duration, age of introduction of complementary foods) in the four European cohorts under study as well as the mean ( \pm standard deviation, SD) values of height and BMI $z$-scores as well as fat mass (assessed with BIA or DXA) data in these cohorts.

Figure 1 presents the prevalence of overweight/obesity in all cohorts and age groups as well as differences derived from the comparisons among cohorts with data on 4-year-old children and between age groups within the ALSPAC cohort. Regarding differences among cohorts, the prevalence of overweight/obesity did not differ significantly among 4-year-old children in Greece, Portugal, and the UK. However, for 5-year-old children in France (EDEN study), the prevalence of overweight/obesity was found to be much lower compared to the 4-year-old children from the other three cohorts ( 7 vs. 20\%). Regarding differences within ALSPAC, the prevalence of overweight/obesity was found to be significantly higher in 9-year-old children compared to 4- and 13-year-old children [i.e. 22 vs. $20 \%(P=0.0015)$ and $19.4 \%$ $(P=0.0001)$, respectively]. 
Table 1 Descriptive characteristics of preschool children in four European cohorts as well as schoolchildren and adolescents in UK and their mothers

\begin{tabular}{|c|c|c|c|c|c|c|}
\hline & $\begin{array}{l}\text { Greek-EuroPrevall at } \\
\text { age } 4 \text { years } \\
n=309\end{array}$ & $\begin{array}{l}\text { Generation XXI at } \\
\text { age } 4 \text { years } \\
n=3387\end{array}$ & $\begin{array}{l}\text { EDEN at age } \\
5 \text { years } \\
n=1070\end{array}$ & $\begin{array}{l}\text { ALSPAC at age } \\
4 \text { years } \\
n=6522\end{array}$ & $\begin{array}{l}\text { ALSPAC at age } \\
9 \text { years } \\
n=7540\end{array}$ & $\begin{array}{l}\text { ALSPAC at age } \\
13 \text { years } \\
n=6124\end{array}$ \\
\hline \multicolumn{7}{|l|}{ Maternal age (\%) } \\
\hline$<25$ years & 0 & 18.7 & 11.2 & 19.6 & 19.6 & 19.2 \\
\hline $25-35$ years & 36.7 & 67.7 & 70.3 & 71.5 & 71.6 & 71.3 \\
\hline$>35$ years & 63.3 & 13.6 & 18.4 & 8.9 & 8.8 & 9.5 \\
\hline \multicolumn{7}{|l|}{ Maternal BMI (\%) } \\
\hline Missing & 0 & 0 & 0 & 8.7 & 8.7 & 7.8 \\
\hline$<18.5 \mathrm{~kg} / \mathrm{m}^{2}$ & 3.7 & 3.8 & 8.4 & 9.8 & 9.8 & 9.4 \\
\hline $18.5-24.9 \mathrm{~kg} / \mathrm{m}^{2}$ & 54.1 & 65.3 & 84.3 & 64.3 & 64.3 & 65.8 \\
\hline $25.0-29.9 \mathrm{~kg} / \mathrm{m}^{2}$ & 29.4 & 22.3 & 6.1 & 12.7 & 12.7 & 12.8 \\
\hline$\geq 30 \mathrm{~kg} / \mathrm{m}^{2}$ & 12.8 & 8.5 & 1.2 & 4.5 & 4.5 & 4.2 \\
\hline \multicolumn{7}{|c|}{ Any breastfeeding duration (\%) } \\
\hline Never & 20.4 & 8.0 & 25.7 & 24.8 & 20.4 & 21.1 \\
\hline$<1$ months & 15.5 & 3.9 & 6.4 & 10.5 & 10.2 & 11.5 \\
\hline$\geq 1$ to $<3$ months & 23.8 & 12.4 & 21 & 13.1 & 13.0 & 13.7 \\
\hline$\geq 3$ to $<6$ months & 17 & 18.9 & 21.4 & 16.6 & 17.5 & 8.0 \\
\hline$\geq 6$ months & 23.3 & 56.8 & 25.5 & 34.9 & 38.9 & 45.7 \\
\hline \multicolumn{7}{|c|}{ Age of introduction of complementary foods (\%) } \\
\hline$<4$ months & 0 & $6.4^{*}$ & 29.1 & 72.3 & 71.5 & 70.8 \\
\hline$\geq 4$ to $<5$ months & 0 & $52.5^{*}$ & 17.9 & 23.7 & 24.7 & 25.3 \\
\hline$\geq 5$ to $<6$ months & 14.1 & $17.9^{*}$ & 20.3 & 3.2 & 3.2 & 3.3 \\
\hline$\geq 6$ months & 85.9 & $23.2^{*}$ & 32.8 & 0.7 & 0.6 & 0.5 \\
\hline \multicolumn{7}{|c|}{ Antropometric and body composition indices [mean $( \pm \mathrm{SD})]$} \\
\hline Height $z$-score & $0.61( \pm 1.09)$ & $0.06( \pm 0.95)$ & $0.22( \pm 0.97)$ & $0.74( \pm 0.98)$ & $0.3( \pm 1)$ & $0.4( \pm 1)$ \\
\hline BMI $z$-score & $0.57( \pm 1.08)$ & $0.62( \pm 1.1)$ & $0.04( \pm 0.86)$ & $0.75( \pm 0.99)$ & $0.37( \pm 1.1)$ & $0.23( \pm 1.1)$ \\
\hline Fat mass (BIA) (kg) & $4.74( \pm 2.2)$ & $3.11( \pm 1.9)$ & $4.59( \pm 1.7)$ & N/A & $4.75( \pm 6.1)$ & $9.55( \pm 9.5)$ \\
\hline $\begin{array}{l}\text { Fat mass (DXA) (\% of } \\
\text { body weight) }\end{array}$ & N/A & N/A & N/A & N/A & $23.2( \pm 9.1)$ & $24.1( \pm 10)$ \\
\hline
\end{tabular}

$* n=419$

\section{Multivariate regression analyses}

\section{Outcome: height z-score}

When height was investigated as an outcome (Fig. 2), 4-yearold children in ALSPAC that were never breastfed and those breastfed between 1 and 3 months of age were found to have

\section{Prevalence of overweight/ obesity (\%)}

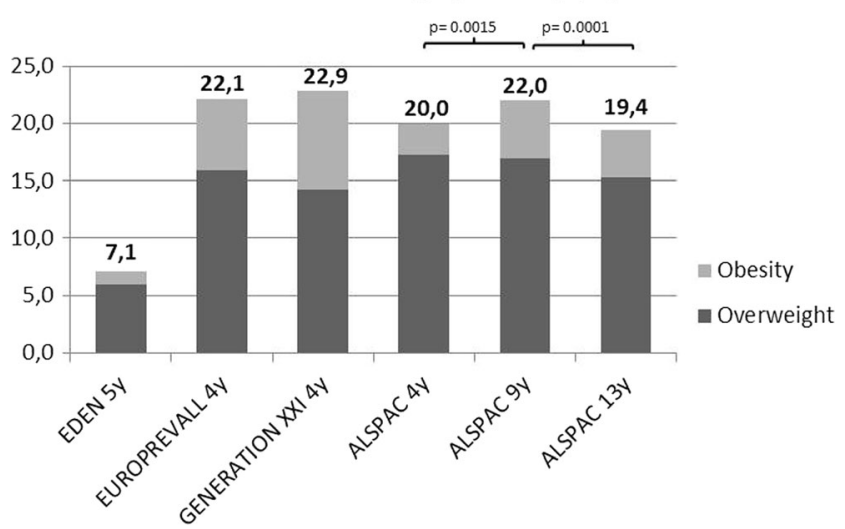

Fig. 1 Prevalence of overweight and obesity among preschool children in four European cohorts as well as schoolchildren and adolescents in UK (weight categories based on IOTF growth standards) higher height $z$-scores compared to children breastfed for 6 or more months of age $(P=0.006)$. In contrast, 5 -year-old children in EDEN that were never breastfed and those breastfed from 1 to 6 months of age $(P=0.0004)$ were found to have lower height $z$-scores compared to children breastfed for 6 or more months. Furthermore, 4-year-old children in Generation XXI to whom complementary foods were introduced after 6 months of age had lower height $z$-scores than children to whom complementary foods were introduced between 5 and 6 months of age $(P=0.049)$. No other significant associations were observed, showing that early feeding practices are not consistently related to height $z$-score in preschool children in the four European cohorts.

\section{Outcome: overweight/obesity prevalence}

When investigating overweight/obesity prevalence as an outcome (Fig. 3), 4- and 13-year-old children in ALSPAC that were breastfed between 3 and 6 months of age were less likely to be overweight or obese $(P=0.008$ at 4 years and $p=0.031$ at 13 years) than those breastfed for longer than 6 months. However, the associations for preschool children observed in the other cohorts were not statistically significant. 


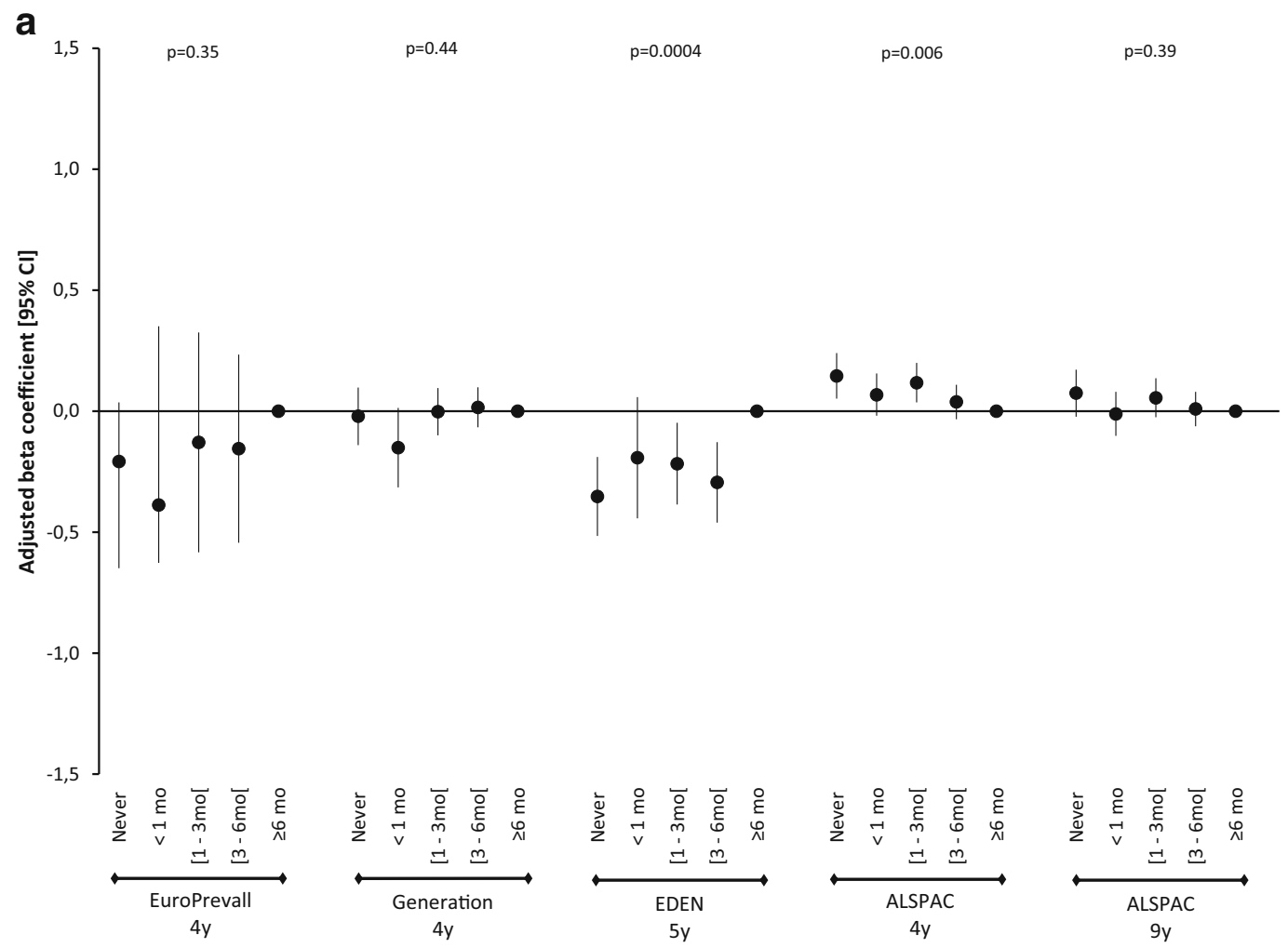

b

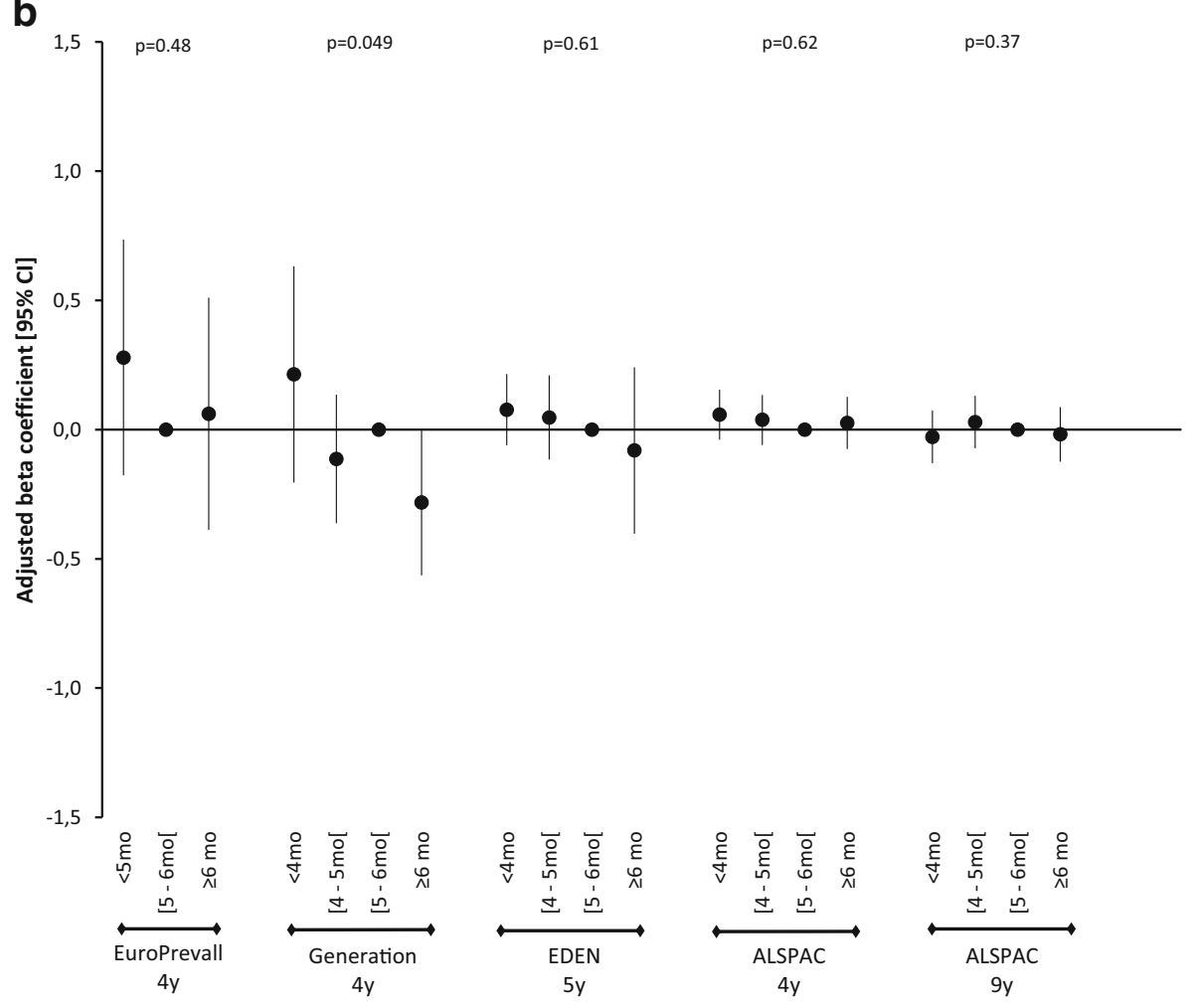

Fig. 2 Association of any breastfeeding duration (a) and age of introduction of complementary feeding (b) with height $z$-score. Multivariate linear regression model adjusted for birth weight category, child's gender, maternal age, maternal educational level, and maternal pre-pregnancy BMI. Furthermore, the analyses presented in Fig. 2a were

also adjusted for the age of introduction of complementary feeding (with the exception of the Generation XXI study), and the analyses presented in Fig. $2 \mathrm{~b}$ were also adjusted for any breastfeeding duration. $C I$ confidence interval 

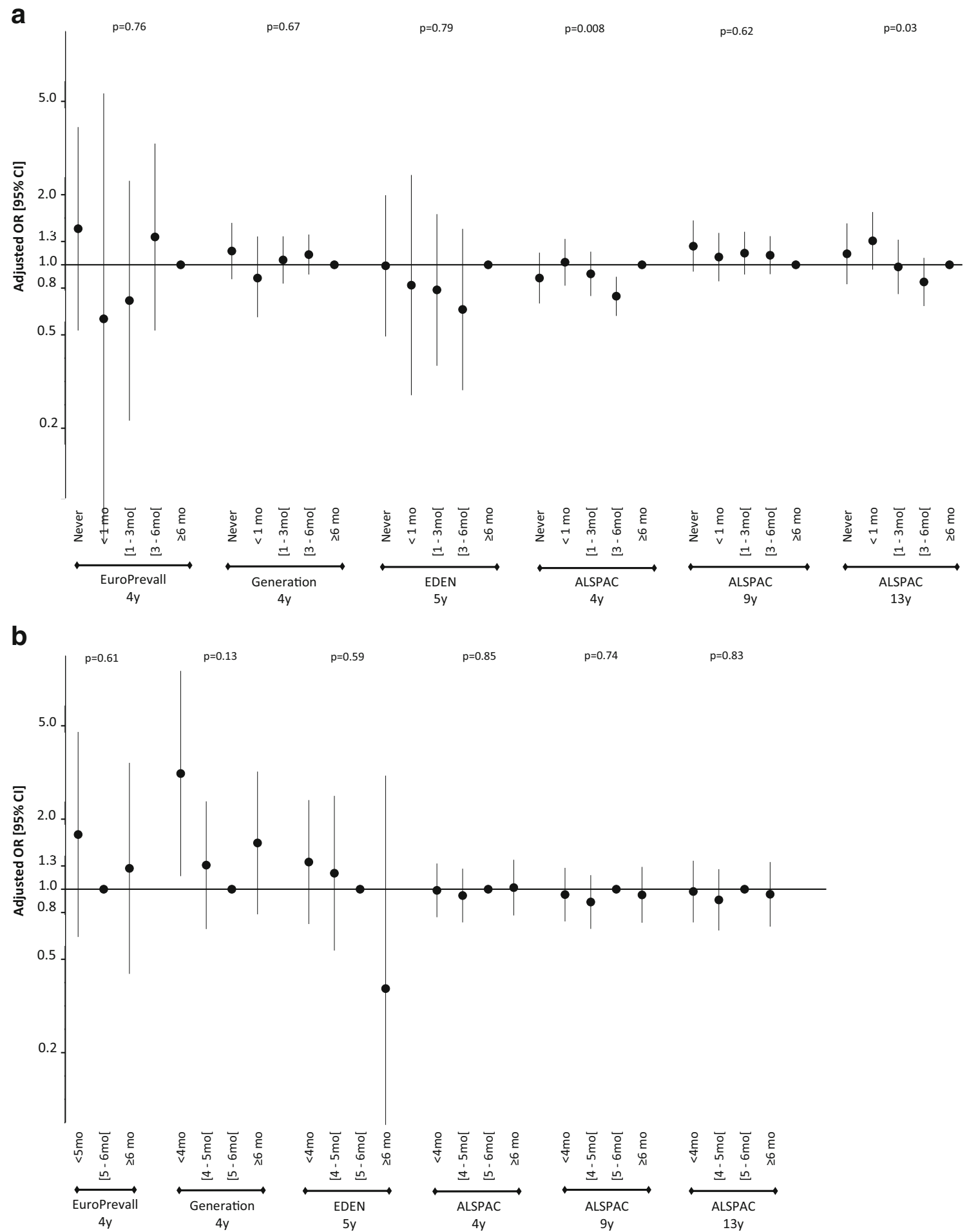

Fig. 3 Association between any breastfeeding duration (a) and age of introduction of complementary feeding (b) with overweight/obesity prevalence. Multivariate linear regression model adjusted for birth weight category, child's gender, maternal age, maternal educational level, and maternal pre-pregnancy BMI. Furthermore, the analyses presented in a

were also adjusted for the age of introduction of complementary feeding (with the exception of the Generation XXI study), and the analyses presented in $\mathbf{b}$ were also adjusted for any breastfeeding duration. $C I$ confidence interval

Outcome: fat mass levels

less than 1 month had higher body fat mass levels (measured with BIA) compared to children breastfed for more

When body fat mass was examined as an outcome (Figs. 4 and 5), 13-year-old children in ALSPAC breastfed for than 6 months $(P=0.030)$. In contrast, 13-year-old children in ALSPAC that were breastfed from 3 to 6 months 


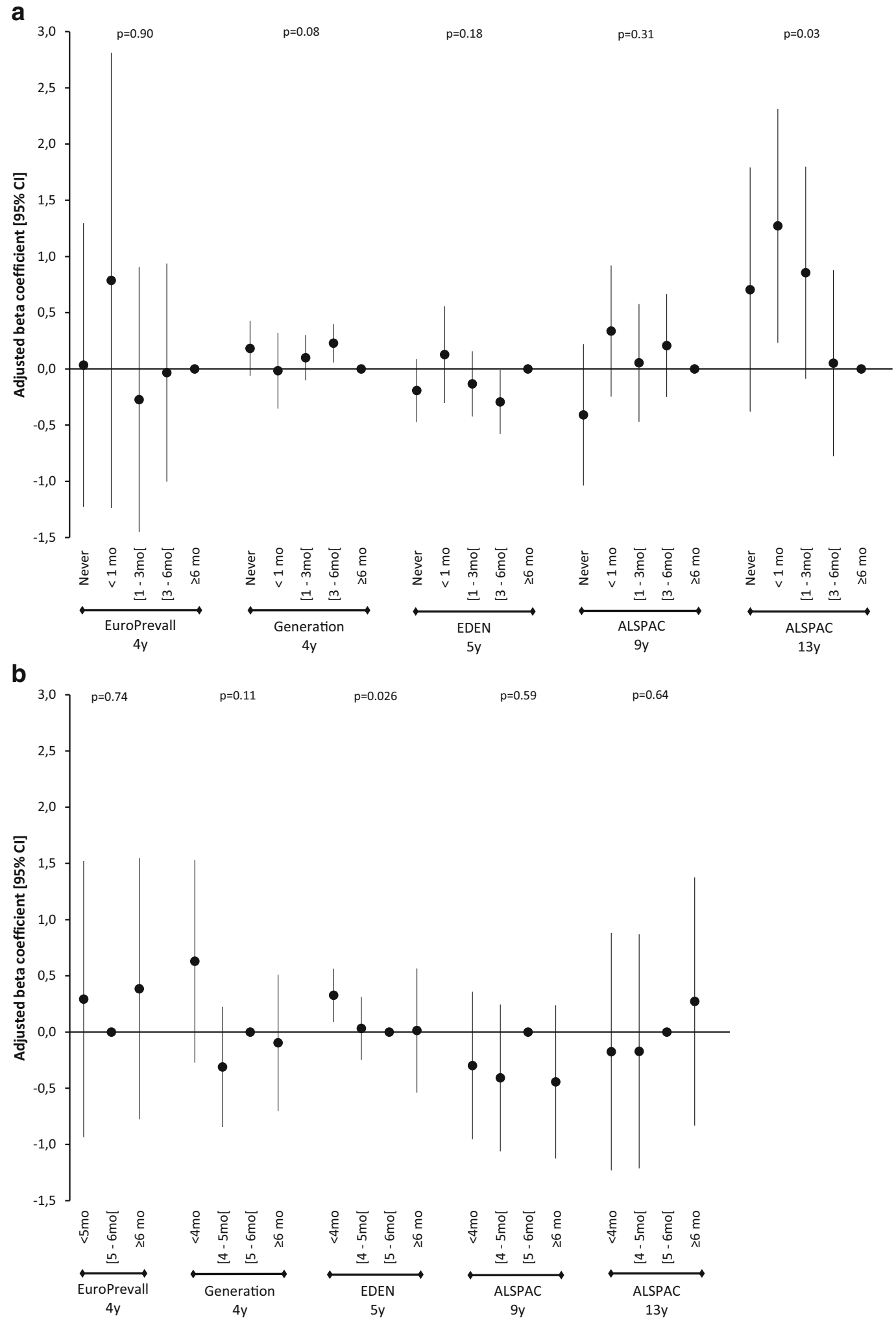

Fig. 4 Association between any breastfeeding duration (a) and age of introduction of complementary feeding (b) with fat mass assessed with BIA. Multivariate linear regression model adjusted for birth weight category, child's gender, maternal age, maternal educational level, and maternal pre-pregnancy BMI. Furthermore, the analyses presented in a

were also adjusted for the age of introduction of complementary feeding (with the exception of the Generation XXI study) and the analyses presented in $\mathbf{b}$ were also adjusted for any breastfeeding duration. $\mathrm{CI}$ confidence interval 
of age were found to have lower body fat mass levels (measured with DXA) compared to their peers that were breastfed for more than 6 months of age $(P=0.025)$ (Fig. 5). Lastly, 5-year-old children in EDEN to whom complementary feeding was introduced before 4 months of age were found to have higher fat mass levels compared to their counterparts to whom complementary feeding was introduced between 5 and 6 months of age $(P=0.046)$. Summarizing these results and also considering the non-significant findings observed in the other cohorts in their majority, these associations showed no effect of early feeding practices on body fat mass (assessed either by BIA or DXA) in preschool children and/or adolescents.

\section{Children's current food habits}

Additional adjustments were made for the child's fruit and vegetable intake and the HPVS in the association between early feeding practices and childhood growth and adiposity indices. However, these additional adjustments did not affect the associations previously described (data not shown).

\section{Discussion}

Similar to the previous literature [28], early feeding practices, i.e., any breastfeeding duration and age of introduction of complementary feeding during infancy, were not found to be consistently associated with growth and obesity indices in preschool children in the four European prospective cohorts examined in the current study.

These inconsistent findings observed in the current work could possibly be due to the different data collection procedures. Furthermore, differences in genetic predisposition as well as in cultural, sociodemographic, lifestyle, and other aspects among countries produce a complex mosaic of interacting factors that could modify and/or confound the associations observed in the current work between early feeding practices, growth, and adiposity indices [21]. In an attempt to control for the effect of such factors, all multivariate regression models performed in the current work to test the associations of early feeding practices with later growth and adiposity indices were adjusted for a wide range of possible confounders (and/or effect modifiers). Among these possible confounders, child's fruit and vegetable intake and HPVS were also included in the analyses, but the associations between early feeding practices and growth and adiposity indices were not affected. While previous
Fig. 5 Association between any breastfeeding duration (a) and age of introduction of complementary feeding (b) with fat mass assessed with DXA. Multivariate linear regression model adjusted for birth weight category, child's gender, maternal age, maternal educational level, and maternal pre-pregnancy BMI.

Furthermore, the analyses presented in a were also adjusted for the age of introduction of complementary feeding, and the analyses presented in $\mathbf{b}$ were also adjusted for any breastfeeding duration. $C I$ confidence interval a

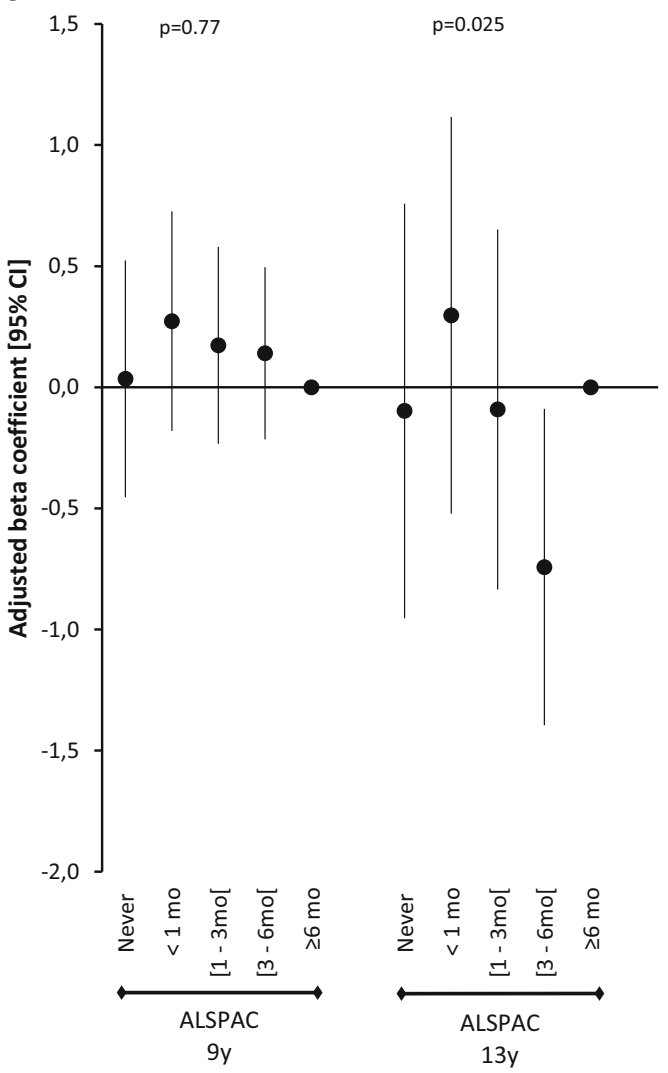

b

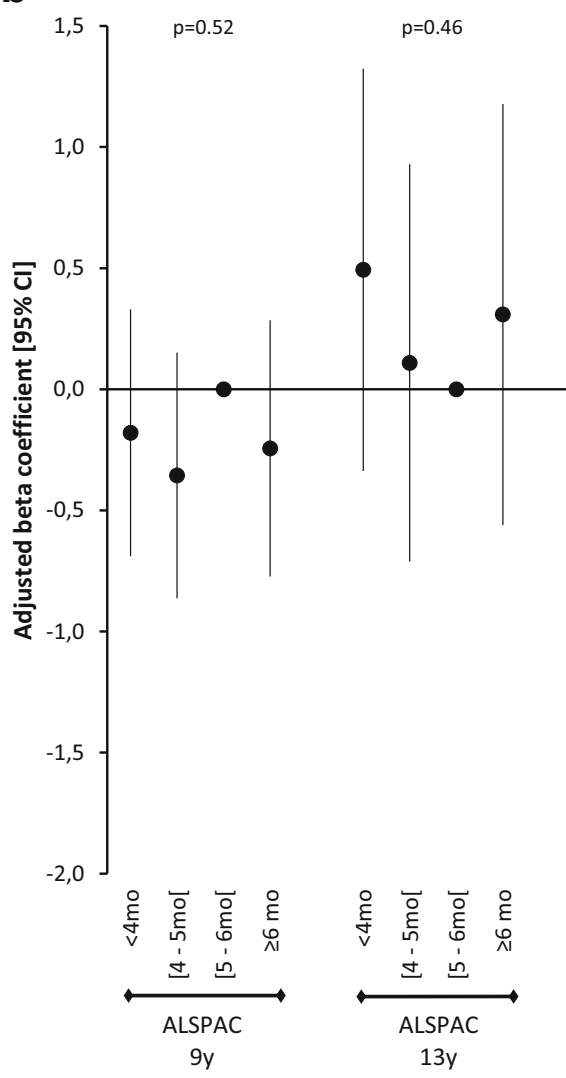


findings from the HabEat project have revealed a significant positive association between breastfeeding duration and later consumption of fruit and vegetables in the same four cohorts [7], based on the current findings, fruit and vegetables consumption does not seem to have a confounding or modifying effect on the associations of child's early feeding practices with growth and obesity in later childhood.

Most studies up to date have mainly examined the associations between early feeding practices and obesity in later life but not with growth indices. Regarding breastfeeding, the majority of studies have examined the association of "ever breastfed" (which includes exclusive breastfeeding or mixed feeding, i.e., a mixture of breast milk and formula, during the first year of life) with overweight and obesity in later years and have reported inconsistent findings. In this regard, although several prospective studies included in a recent meta-analysis showed that ever breastfed versus non-breastfed infants had a $15 \%$ lower risk of overweight in early childhood [28], other recent prospective studies and one randomized controlled trial did not confirm this protective effect $[8,13,24]$. With regard to the timing of complementary feeding, most recent relevant reviews conclude that there is no clear association with the later occurrence of obesity in childhood, since most studies have not found any statistically significant association $[22,25$, $28]$. However, it has been advocated that very early complementary feeding ( $\leq 4$ months of age) rather than 4-6 months or $>6$ months may result in increased BMI in childhood [25], which is consistent with the findings reported by the current work for the Generation XXI study. Similarly, the EDEN study showed a significant association between early complementary feeding with fat mass as this was assessed with BIA.

In addition to the inconsistent findings observed among cohorts in the present study, the absence of statistical significance in the vast majority of the associations between early feeding practices with growth and adiposity indices warrants some further interpretation. One possible reason for the statistically non-significant results could be the low sample sizes that have resulted to lower statistical power (particularly smaller in certain cohorts, e.g., EuroPrevall). In addition to the multifactorial etiology of growth and obesity in childhood, the preschool age of children examined in the current studies (i.e. 4 and 5 years) might provide another such interpretation. More specifically, similar to the current work, most studies failing to report significant associations between early feeding practices and obesity in preschool children were conducted earlier to the adiposity rebound that usually occurs after the age of 5.5 to 6 years [25]. An implication for future research derived from this observation could be the examination of these associations with repeated measures taken prospectively from infancy to adolescence (pre- and post-adiposity rebound), also assessing a wide range of lifestyle, cultural, sociodemographic, and genetic factors.
The current study warrants certain strengths and limitations. Regarding strengths, the prospective design of the four studies included in the current analyses can provide etiological associations which are not possible in crosssectional designs. As far as other strengths are concerned, the current study includes data from different countries in Europe and the analyses were adjusted for several possible confounders available in all four cohorts. Regarding limitations, although the analysis was conducted with similar variables in the four cohorts, still, there were differences in the methodological procedures used to collect the data and perform measurements in each study, thus probably affecting the results of the current work. Furthermore, another limitation could stem from the fact that the same data were not available for all cohorts (e.g. fat mass assessed with BIA was not available for 4 year old children in ALSPAC; fat mass assessed with DXA was only available in 9- and 13year-old children in ALSPAC). In addition to the above, it should be noted that the cohort of the ALSPAC study was recruited during 1991-1992, being at least 12 years apart from the other cohorts (EDEN: 2003-2006, Generation XXI: 2005-2006, EuroPrevall: 2005-2007). The limitations mentioned above derive from the fact that the four cohorts were studied for a variety of purposes and not only for testing the hypothesis of the current paper, as is the case in many similar studies. The prevalence of children's overweight was lower in the EDEN study, but this is consistent with low maternal BMI levels (mean BMI $=23.2 \mathrm{~kg} / \mathrm{m}^{2}$ ) [10] observed in the EDEN cohort and the quite low prevalence of overweight reported for French preschool children [16] as compared to their counterparts from other European countries.

In conclusion, the findings of the current work showed that early feeding practices, i.e., any breastfeeding duration and age of introduction of complementary foods, do not appear to be consistently associated with height $z$-score, overweight/ obesity, and body fat mass in preschool children from four European countries and in UK schoolchildren and adolescents. The numerous and heterogeneous factors having an impact on children's growth and adiposity indices have to be thoroughly recorded and taken into consideration when examining these associations. Therefore, further prospective research is needed to assess these associations of breastfeeding duration and the timing of complementary feeding with growth and adiposity in later childhood and adulthood also controlling for potential confounding factors as indicated by the literature.

Acknowledgements We are grateful to Sylvie Issanchou for her coordination of the HabEat project. We are indebted to all participants for providing the data used in the four birth cohorts, as well as to all members of the research team and coordinators (Nikos Papadopoulos from EuroPrevall, Henrique Barros from Generation XXI, George Davey 
Smith from ALSPAC, and Barbara Heude from the EDEN mother-child Study Group).

Authors' contributions Study concept and design: GM, BLG, LJ, AO, PM, CL, PE, MAC, YM. Acquisition of data: GM, BLG, LJ, AO, LD, PM, CL, PE, MAC, YM. Analysis and interpretation of data: GM, BLG, LJ, AO, CPL, PM, CL, PE, MAC, YM. Drafting of the manuscript: GM. Critical revision of the manuscript for important intellectual content: GM, BLG, LJ, AO, SL, PM, CL, PE, MAC, YM. Final approval of the version to be published: All authors.

\section{Compliance with ethical standards}

Ethical approval This study was conducted according to the guidelines laid down in the Declaration of Helsinki, and all procedures involving human subjects were approved by each institute's ethics committee.

Informed consent Written informed consent was obtained for all subjects included in the study.

Conflict of interest None of the authors has any potential conflict of interest to declare.

Source of funding The research leading to these results has received funding from the European Community's Seventh Framework Program (FP7/2007-2013) under the grant agreement no. FP7-245012-HabEat. ALSPAC was funded by the UK Medical Research Council, the Wellcome Trust and the University of Bristol provided core support for ALSPAC. The EuroPrevall study was funded by the EU through FP6FOOD-CT-2005-514000. Generation XXI was funded by Programa Operacional de Saúde - Saúde XXI, Quadro Comunitário de Apoio III, and by Administração Regional de Saúde Norte. For follow-up assessments, Generation XXI received funding from Fundação para a Ciência e a Tecnologia, co-funded by FEDER through COMPETE and from Fundação Calouste Gulbenkian. Support for the EDEN study (Étude des Déterminants pré- et postnatals précoces du développement et de la santé de l'ENfant) was provided by the following organizations: Fondation pour la Recherche Médicale, French Ministry of Research Institut Fédératif de Recherche and Cohort Program, INSERM Nutrition Research Program, French Ministry of Health Perinatal Program, French Agency for Environment Security (AFFSET), French National Institute for Population Health Surveillance (INVS), Paris-Sud University, French National Institute for Health Education (INPES), Nestlé, Mutuelle Générale de l'Éducation Nationale, French Speaking Association for the Study of Diabetes and Metabolism (Alfediam), National Agency for Research (ANR nonthematic program), and National Institute for Research in Public Health (IRESP TGIR Cohorte Santé 2008 Program). The study sponsors were not involved in the study design, data collection, or data analyses.

\section{References}

1. Budge H, Sebert S, Sharkey D, Symonds ME (2009) Session on 'Obesity'. Adipose tissue development, nutrition in early life and its impact on later obesity. Proc Nutr Soc 68(3):321-326

2. Butte NF (2009) Impact of infant feeding practices on childhood obesity. J Nutr 139(2):412S-416S

3. Cole TJ, Bellizzi MC, Flegal KM, Dietz WH (2000) Establishing a standard definition for child overweight and obesity worldwide: international survey. BMJ 320(7244):1240-1243

4. Cope MB, Allison DB (2008) Critical review of the World Health Organization's (WHO) 2007 report on 'evidence of the long-term effects of breastfeeding: systematic reviews and meta-analysis' with respect to obesity. Obes Rev 9(6):594-605

5. Corvalan C, Kain J, Weisstaub G, Uauy R (2009) Impact of growth patterns and early diet on obesity and cardiovascular risk factors in young children from developing countries. Proc Nutr Soc 68(3): 327-337

6. Cox DR, Skinner JD, Carruth BR, Moran J 3rd, Houck KS (1997) A Food Variety Index for Toddlers (VIT): development and application. J Am Diet Assoc 97(12):1382-1386 quiz 1387-8

7. de Lauzon-Guillain B, Jones L, Oliveira A, Moschonis G, Betoko A, Lopes C, Moreira P, Manios Y, Papadopoulos NG, Emmett P, Charles MA (2013) The influence of early feeding practices on fruit and vegetable intake among preschool children in 4 European birth cohorts. Am J Clin Nutr 98(3):804-812

8. Durmus B, van Rossem L, Duijts L, Arends LR, Raat H, Moll HA, Hofman A, Steegers EA, Jaddoe VW (2011) Breast-feeding and growth in children until the age of 3 years: the Generation $\mathrm{R}$ Study. Br J Nutr 105(11):1704-1711

9. Hales CN, Barker DJ (2001) The thrifty phenotype hypothesis. Br Med Bull 60:5-20

10. Heude B, Forhan A, Slama R, Douhaud L, Bedel S, SaurelCubizolles MJ, Hankard R, Thiebaugeorges O, De Agostini M, Annesi-Maesano I, Kaminski M, Charles MA (2016) Cohort profile: the EDEN mother-child cohort on the prenatal and early postnatal determinants of child health and development. Int J Epidemiol 45(2):353-363

11. Hornell A, Lagstrom H, Lande B, Thorsdottir I (2013) Breastfeeding, introduction of other foods and effects on health: a systematic literature review for the 5 th Nordic Nutrition Recommendations. Food Nutr Res 57

12. Ip S, Chung M, Raman G, Chew P, Magula N, DeVine D, Trikalinos T, Lau J (2007) Breastfeeding and maternal and infant health outcomes in developed countries. Evid Rep Technol Assess (Full Rep) 153:1-186

13. Kramer MS, Matush L, Vanilovich I, Platt RW, Bogdanovich N, Sevkovskaya Z, Dzikovich I, Shishko G, Collet JP, Martin RM, Davey Smith G, Gillman MW, Chalmers B, Hodnett E, Shapiro S et al (2007) Effects of prolonged and exclusive breastfeeding on child height, weight, adiposity, and blood pressure at age $6.5 \mathrm{y}$ : evidence from a large randomized trial. Am J Clin Nutr 86(6): $1717-1721$

14. Lamb MM, Dabelea D, Yin X, Ogden LG, Klingensmith GJ, Rewers M, Norris JM (2010) Early-life predictors of higher body mass index in healthy children. Ann Nutr Metab 56(1):16-22

15. Larsen PS, Kamper-Jorgensen M, Adamson A, Barros H, Bonde JP, Brescianini S, Brophy S, Casas M, Charles MA, Devereux G, Eggesbo M, Fantini MP, Frey U, Gehring U, Grazuleviciene R et al (2013) Pregnancy and birth cohort resources in Europe: a large opportunity for aetiological child health research. Paediatr Perinat Epidemiol 27(4):393-414

16. Lioret S, Touvier M, Dubuisson C, Dufour A, Calamassi-Tran G, Lafay L, Volatier JL, Maire B (2009) Trends in child overweight rates and energy intake in France from 1999 to 2007: relationships with socioeconomic status. Obesity (Silver Spring) 17(5):1092-1100

17. Lucas A (1994) Role of nutritional programming in determining adult morbidity. Arch Dis Child 71(4):288-290

18. Lucas A (1998) Programming by early nutrition: an experimental approach. J Nutr 128(2 Suppl):401S-406S

19. Manios Y, Moschonis G, Grammatikaki E, Anastasiadou A, Liarigkovinos T (2010) Determinants of childhood obesity and association with maternal perceptions of their children's weight status: the “GENESIS" study. J Am Diet Assoc 110(10):1527-1531

20. McBride D, Keil T, Grabenhenrich L, Dubakiene R, Drasutiene G, Fiocchi A, Dahdah L, Sprikkelman AB, Schoemaker AA, Roberts 
G, Grimshaw K, Kowalski ML, Stanczyk-Przyluska A, Sigurdardottir S, Clausen M et al (2012) The EuroPrevall birth cohort study on food allergy: baseline characteristics of 12,000 newborns and their families from nine European countries. Pediatr Allergy Immunol 23(3):230-239

21. Monasta L, Batty GD, Cattaneo A, Lutje V, Ronfani L, Van Lenthe FJ, Brug J (2010) Early-life determinants of overweight and obesity: a review of systematic reviews. Obes Rev 11(10):695-708

22. Moorcroft KE, Marshall JL, McCormick FM (2011) Association between timing of introducing solid foods and obesity in infancy and childhood: a systematic review. Matern Child Nutr 7(1):3-26

23. Moschonis G, Grammatikaki E, Manios Y (2008) Perinatal predictors of overweight at infancy and preschool childhood: the GENESIS study. Int J Obes 32(1):39-47

24. Novaes JF, Lamounier JA, Colosimo EA, Franceschini SC, Priore SE (2012) Breastfeeding and obesity in Brazilian children. Eur J Pub Health 22(3):383-389
25. Pearce J, Taylor MA, Langley-Evans SC (2013) Timing of the introduction of complementary feeding and risk of childhood obesity: a systematic review. Int J Obes 37(10):1295-1306

26. Schaefer F, Georgi M, Zieger A, Scharer K (1994) Usefulness of bioelectric impedance and skinfold measurements in predicting fatfree mass derived from total body potassium in children. Pediatr Res 35(5):617-624

27. Symonds ME, Mendez MA, Meltzer HM, Koletzko B, Godfrey K, Forsyth S, van der Beek EM (2013) Early life nutritional programming of obesity: mother-child cohort studies. Ann Nutr Metab 62(2):137-145

28. Weng SF, Redsell SA, Swift JA, Yang M, Glazebrook CP (2012) Systematic review and meta-analyses of risk factors for childhood overweight identifiable during infancy. Arch Dis Child 97(12): $1019-1026$ 